\title{
Risk of Diabetes in Cameroonian Patients with Psychosis and Under Antipsychotic Therapy: A Cross-Sectional Study
}

\author{
Hermine Raissa Hell ${ }^{1,2, *}$, Maxwell Nguedjo Wandji ${ }^{1,3}$, Celine Sylvie Mimboe Bilongo ${ }^{1}$, \\ Ruth Edwige Dibacto Kemadjou ${ }^{1,3}$, Boris Ronald Tchuente Tonou ${ }^{1,3}$, Therese Henriette Dimodi ${ }^{1}$, \\ Gabriel Medoua Nama ${ }^{1}$, Olga Yvonne Mankollo Bassong ${ }^{2}$ \\ ${ }^{1}$ Centre for Food and Nutrition Research, Institute of Medical Research and Medicinal Plants Studies, Ministry of Scientific Research and \\ Innovation, Yaounde, Cameroon \\ ${ }^{2}$ Department of Public Health, School of Health Sciences, Catholic University of Central Africa, Yaounde, Cameroon \\ ${ }^{3}$ Laboratory of Nutrition and Nutritional Biochemistry, University of Yaounde, Yaounde, Cameroon
}

\author{
Email address: \\ helraissa@yahoo.fr (H. R. Hell) \\ ${ }^{*}$ Corresponding author
}

\section{To cite this article:}

Hermine Raissa Hell, Maxwell Nguedjo Wandji, Celine Sylvie Mimboe Bilongo, Ruth Edwige Dibacto Kemadjou, Boris Ronald Tchuente Tonou, Therese Henriette Dimodi, Gabriel Medoua Nama, Olga Yvonne Mankollo Bassong. Risk of Diabetes in Cameroonian Patients with Psychosis and Under Antipsychotic Therapy: A Cross-Sectional Study. Central African Journal of Public Health.

Vol. 6, No. 6, 2020, pp. 365-371. doi: 10.11648/j.cajph.20200606.18

Received: October 13, 2020; Accepted: December 23, 2020; Published: December 31, 2020

\begin{abstract}
Background: Diabetes is a public health problem worldwide and in sub-Saharan African countries such as Cameroon. According to many studies, the use of antipsychotic drugs increases the risk of developing diabetes mellitus by 2 to 3 times more in people with psychotic disorders than in the general population. The present study aimed to assess the influence of antipsychotic drugs used on the risk of developing diabetes and to identify other factors predictive of abnormal blood glucose levels in patients suffering from psychosis. Methods: A cross-sectional study was conducted from the 3rd to the 19th of January 2018. Patients aged at least 18 years old suffering from psychosis and undiagnosed as diabetic before initiation of antipsychotic treatment were recruited at the Jamot Hospital in Yaoundé. A questionnaire was used to collect sociodemographic, anthropometric, and clinical data. The Chi-Square test was used to assess the relationship between hyperglycemia and categorical variables and the multivariate logistic regression model was used to determine independent predictors of hyperglycemia through the Statistical Package for the Social Sciences (SPSS) version 20.0. Results: A total of 82 patients were included in the study ( 41 males and 41 females). The fasting blood sugar $\geq 100 \mathrm{mg} / \mathrm{dL}$ appeared to be higher but not significant in patients on atypical antipsychotic therapy $(124.74 \pm 23.31 \mathrm{mg} / \mathrm{dL})$ compared to patients on typical antipsychotic therapy $(115.74 \pm 18.63 \mathrm{mg} / \mathrm{dL})$; with a positive and non-significant correlation between hyperglycemia and duration of treatment $(\mathrm{r}=0.215 ; \mathrm{p}=0.053)$. However, in both typical and atypical antipsychotic patients, fasting glucose sugar levels between $110-125 \mathrm{mg} / \mathrm{dL}$ were observed at the same level $(118.07 \pm 4.84 \mathrm{mg} / \mathrm{dL}$ and $118.09 \pm 3.41 \mathrm{mg} / \mathrm{dL}$ respectively). Male sex $(\mathrm{OR}=1.41 ; 95 \%$ CI $0.54-3.64)$, age group $<35$ years $(\mathrm{OR}=1.84 ; 95 \%$ CI $0.69-4.88)$, single $(\mathrm{OR}=2.18 ; 95 \% \mathrm{CI} 0.83-5.67)$, typical antipsychotic drugs $(\mathrm{OR}=1.12 ; 95 \% \mathrm{CI} 0.42-3.01)$, schizophrenia $(\mathrm{OR}=1.80 ; 95 \% \mathrm{CI}$ $0.25-12.84)$ and bipolar disorder $(\mathrm{OR}=1.50 ; 95 \% \mathrm{CI} 0.14-15.46)$ were independent predictors of hyperglycemia in those patients. Conclusion: Regular monitoring of anthropometric and clinical parameters should be assigned to people suffering from psychotic disorders and under treatment. Therefore, they should benefit from good management of the risk factors for diabetes to prevent the onset of the disease and avoid increased morbidity and mortality in this vulnerable population.
\end{abstract}

Keywords: Risk Factors, Diabetes, Psychosis, Antipsychotic, Duration of Treatment 


\section{Introduction}

Diabetes is a metabolic and endocrine disorder characterized by chronic hyperglycemia resulting from a defect in insulin action and/or secretion [1]. The management of hyperglycaemia when it is diagnosed remains one of the key issues in the prevention of this disease, which is a potential cause of mortality worldwide [2]. In 2019, an estimated $9.3 \%$ (463 million) of the world's population had diabetes [3]. Global projections show that the prevalence of diabetes will reach $10.2 \%$ (578 million) by 2030 . In Africa, there are 19 million adults with diabetes with the highest proportion $(59.7 \%)$ of people with undiagnosed diabetes worldwide [3, 4]. In Cameroon, the prevalence of diabetes in adults is currently estimated at $6-7 \%$, with about $80 \%$ of people in the population with undiagnosed diabetes [3].

Besides, psychotic illnesses are a cause of disability in the individual and contribute significantly to the global burden of disease. For, the use of antipsychotic drugs has increased over the last decade [5]. This increase translates into an increasing prevalence of psychotic disorders. We have gone from $7.49 \%$ per 1000 individuals under antipsychotic drugs in 2018[6], to $26.6 \%$ per $100 \quad 000$ person-years in 2019 [7]. In addition, the use of these antipsychotic drugs has also been associated with an increase in the prevalence of diabetes among people with psychoses compared to the general population [8]. Results from some studies suggest that schizophrenia and bipolar disorder are associated with an increased risk of diabetes; similarly, the incidence of diabetes is increased in people treated with second-generation antipsychotic drugs [9]. Thus, the mechanisms underlying these relationships are governed by multiple factors involving biochemical changes due to mental illness [10]. Similarly, the reasons for the higher metabolic risk in this population would also be associated with sedentary lifestyles, poor dietary habits, socioeconomic conditions, and limited access to medical care [11].

An increasing interest in the relationship between antipsychotic drugs and the risk of developing diabetes has led many studies worldwide, but in Cameroon few studies exist on the relationship between antipsychotic drugs and the risk of developing diabetes. On the other hand, the management of psychotic patients does not include the recording of clinical parameters that may allow the diagnosis of metabolic diseases and promote better follow-up. This study was designed to evaluate the influence of antipsychotic drug use on the risk of developing diabetes and to identify other predictive factors of abnormal increases in blood sugar levels in patients suffering from psychosis.

\section{Methodology}

\subsection{Design and Study Setting}

This is a prospective, cross-sectional study with an analytical focus. This study was conducted within the Psychiatric Department of the Jamot Hospital in Yaounde (Cameroon) for two-weeks from the 3rd to the 19th January
2018. Patients were recruited based on antipsychotic medication intake. This study was authorized by the Director of the Jamot Hospital in Yaounde via the reference $\mathrm{n}^{\circ} 00001731 / \mathrm{MINSANTE} / \mathrm{SG} / \mathrm{DHJY}$ and received the approval of the national ethics committee under n²017/0588/CEIRSH/ESS/MSP. Free and informed consent was obtained from each patient and/or his legal representative. The study was conducted in strict respect of the physical, moral, and psychological integrity of all participants per the principles described in the Declaration of Helsinki.

\subsection{Target Population}

The study population consisted of patients suffering from psychosis followed at the Jamot Hospital in Yaounde (JHY) and undergoing an antipsychotic treatment. Depending on the availability and proximity of respondents, a total of 156 patients with psychosis were approached. From those 156 patients; 40 patients did not give consent; 33 patients were mentally unstable and 1 patient was diabetic before initiation of antipsychotic medication. Only 82 of those patients were recruited for this study.

Inclusion criteria

1. Patients 18 years of age and more;

2. Patients followed at the Jamot Hospital in Yaounde;

3. Patients undergoing antipsychotic treatment at the Jamot Hospital in Yaounde;

4. Patients who have given consent to participate in the study.

Exclusion criteria

1. Patients who refused to participate in the study;

2. Mentally unstable patients (without a guardian and/or with a violent character);

3. Patients diagnosed with diabetes prior to the intake initiation of antipsychotic treatment.

\subsection{Assessment}

The data were collected via a questionnaire in the presence of health care staff and/or a family member of the patient. The questionnaire contained information on sociodemographic characteristics (gender, age, marital status, education, and occupation), the different antipsychotic drugs administered, the duration of treatment, the family history of diabetes, and the type of psychological illness the patient had.

The different antipsychotic drugs administered to patients have been grouped into two classes: typical antipsychotics (Haloperidol, Chlorpromazine, Nozinan, Modecate) and atypical antipsychotics (Risperidone, Olanzapine, Quetiapine, Clozapine, Aripiprazole).

Weight (to the nearest kilogram) and height (to the nearest centimeter) were measured according to standard methods. Body mass index (BMI) was calculated by dividing weight by height squared. Blood pressure was measured using a Life Source electric blood pressure monitor on the participant's left arm while seated after at least 10 minutes of rest. Fasting 
blood glucose was measured by the glucose oxidase method using a glucose meter and test strips (One-touch plus) directly on the participant's fingertip.

The results of impaired carbohydrate metabolism as hyperglycemia and prediabetes were diagnosed with fasting blood sugar levels $\geq 100 \mathrm{mg} / \mathrm{dL}$ and between $110-125 \mathrm{mg} / \mathrm{dL}$ respectively by the definitions of IDF [12] and WHO [13]. The nutritional status of patients was defined based on BMI using WHO criteria as follows: Normal weight was defined as a BMI between $18.5-24.9 \mathrm{~kg} / \mathrm{m}^{2}$ and overweight as a BMI $\geq 25 \mathrm{~kg} / \mathrm{m}^{2}[14]$.

\subsection{Statistical Analysis}

The statistical analyses were performed using the Statistical Package for the Social Sciences (SPSS) version 20.0. Categorical variables were summarized as percentages while continuous variables were summarized as mean \pm standard deviation. The Chi-Square test was used to assess the relationship between hyperglycemia and categorical variables. The Student t-test was used to detect differences in means between two groups of a continuous dependent variable. Spearman's correlation was used for associations between categorical variables in pairs. The relevant variables and the variable with a value of $p<0.05$ were entered into a multivariate logistic regression model to determine independent predictors of hyperglycemia. Values of $p<0.05$ were considered statistically significant.

\section{Results}

Table 1 shows that the study population consisted of many women as well as men $(50 \%) .65 .4 \%$ of the patients were under 35 years of age while $34.1 \%$ were over 35 years. Concerning the marital status, $57.3 \%$ of patients were single and $42.7 \%$ of patients were living with a partner. For education, most of the patients involved in the study had at least the secondary level $(90.2 \%)$ while few of them $(9.8 \%)$ of the patients had no more than primary school education. As for the patients' occupation, those in self-employment were the most represented (41.5\%).

Anthropometric and clinical characteristics of the study population as a function of treatment duration (Table 2) show that the mean age, weight, Body Mass Index (BMI), diastolic blood pressure, and blood glucose levels were higher but not significant in patients on antipsychotic therapy for more than 6 months compared to patients on antipsychotic therapy of 6 months or less.. Regarding the nutritional status of patients, $46.3 \%$ were of normal weight, with as many patients on treatment for up to 6 months as patients on treatment for more than 6 months (50\%); while $53.7 \%$ of patients were overweight, with $38.6 \%$ on treatment for up to 6 months and $61.4 \%$ on treatment for more than 6 months. In terms of the type of antipsychotic medication given to patients, $65.1 \%$ of patients were on typical antipsychotic medication, $40 \%$ were on treatment for 6 months or less and $59.3 \%$ were on treatment for more than 6 months, while $33.7 \%$ of patients were on atypical antipsychotic medication, $50 \%$ were on treatment for 6 months or less and 50\% were on treatment for more than 6 months. As for neuroleptic diseases, patients with other psychotic disorders were the most represented $31.7 \%$, with $50 \%$ on treatment for 6 months or less and $50 \%$ on treatment for more than 6 months.

Table 3 shows that the overall mean blood glucose levels of patients on atypical antipsychotic therapy are higher in both those with a blood glucose $\geq 100 \mathrm{mg} / \mathrm{dL}$ $(124.74 \pm 23.31 \mathrm{mg} / \mathrm{dL})$ and those with a blood glucose level of $110-125 \mathrm{mg} / \mathrm{dL}(118.09 \pm 3.41 \mathrm{mg} / \mathrm{dL})$ compared to patients on typical antipsychotic therapy where mean blood glucose $\geq 100 \mathrm{mg} / \mathrm{dL}$ is $115.74 \pm 18.63 \mathrm{mg} / \mathrm{dL}$ and blood glucose (110$125 \mathrm{mg} / \mathrm{dL}$ ) is $118.07 \pm 4.84 \mathrm{mg} / \mathrm{dL}$. Concerning the effect of type of antipsychotic medication on blood glucose levels by the duration of treatment, it was found that the mean blood glucose levels in patients with typical and atypical blood glucose $\geq 100 \mathrm{mg} / \mathrm{dL}$ on typical and atypical antipsychotic therapy were higher for those on therapy for more than 6 months $(116.48 \pm 19.33 \mathrm{mg} / \mathrm{dL}$ and $127.18 \pm 23.10 \mathrm{mg} / \mathrm{dL}$ respectively) compared to those on treatment for up to 6 months $(114.31 \pm 17.87 \mathrm{mg} / \mathrm{dL}$ and $121.38 \pm 24.75 \mathrm{mg} / \mathrm{dL}$ respectively). Similarly, in patients on typical and atypical antipsychotic therapy, mean blood glucose levels (110-125 $\mathrm{mg} / \mathrm{dL}$ ) were higher for those on treatment longer than 6 months compared to those on treatment up to 6 months.

Table 4 shows that regardless of the risk factor studied, the prevalence of hyperglycemia was higher in patients on antipsychotic therapy for more than 6 months. Only neuroleptic diseases had significantly different prevalences of hyperglycemia between patients on treatment for 6 months or less and those on antipsychotic therapy for 6 months or more $(\mathrm{p}<0.05)$.

Table 5 shows that in the general population, male sex $(\mathrm{OR}=1.41 ; 95 \%$ CI $0.54-3.64)$, age group $<35$ years $(\mathrm{OR}=1.84 ; 95 \%$ CI $0.69-4.88)$, education level $\geq$ secondary $(\mathrm{OR}=2.52 ; 95 \%$ CI $0.57-11.03)$, single $(\mathrm{OR}=2.18 ; 95 \% \mathrm{CI}$ 0.83-5.67), typical antipsychotics $(\mathrm{OR}=1.12$; 95\% CI 0.42 3.01), schizophrenia (OR=1.80; 95\% CI 0.25-12.84), bipolar disorder $(\mathrm{OR}=1.50 ; 95 \% \mathrm{CI} 0.14-15.46)$ and other psychotic disorders $(\mathrm{OR}=1.35 ; 95 \%$ CI $0.20-9.12)$ were independent predictors of hyperglycemia.

The study of correlations, making it possible to assess the level of association between the different risk factors (Table 6 ), showed that there is a positive and significant correlation between sex and neuroleptic diseases $(r=0.305 ; \mathrm{p}=0.005)$, between BMI and the type of antipsychotic drug $(\mathrm{r}=0.308$; $\mathrm{p}=0.005$ ). Also, a positive but non-significant correlation was observed between hyperglycemia and duration of treatment $(\mathrm{r}=0.215 ; \mathrm{p}=0.053)$ and between BMI and duration of treatment $(\mathrm{r}=0.114 ; \mathrm{p}=0.307)$. 
Table 1. Socio-demographic characteristics of the study population.

\begin{tabular}{llll}
\hline Variable & & Frequency (n) & Percentage (\%) \\
\hline \multirow{2}{*}{ Sex } & Man & 41 & 50.0 \\
& Woman & 41 & 50.0 \\
Age & $<35$ years & 54 & 65.9 \\
& $\geq 35$ years & 28 & 34.1 \\
Marital status & Single & 47 & 57.3 \\
& Married & 35 & 42.7 \\
Education level & At most primary & 8 & 9.8 \\
& $\geq$ Secondary & 74 & 90.2 \\
Profession & Unemployed & 24 & 29.3 \\
& Self- employment & 34 & 41.5 \\
& Private Sector & 12 & 14.6 \\
\hline
\end{tabular}

Table 2. Anthropometric and clinical characteristics of the study population by the duration of treatment.

\begin{tabular}{|c|c|c|c|c|c|}
\hline \multirow{2}{*}{\multicolumn{2}{|c|}{ Variable }} & \multirow{2}{*}{ General population } & \multicolumn{2}{|c|}{ Duration of treatment } & \multirow{2}{*}{ P-value } \\
\hline & & & $\leq 6$ months & $>6$ months & \\
\hline \multicolumn{2}{|l|}{ Age (years) } & $32.70 \pm 10.39$ & $31.67 \pm 10.39$ & $33.50 \pm 11.04$ & 0.446 \\
\hline \multicolumn{2}{|l|}{ Weight (g) } & $75.82 \pm 14.38$ & $75.19 \pm 13.63$ & $76.30 \pm 15.06$ & 0.731 \\
\hline \multicolumn{2}{|c|}{ Body Mass Index $\left(\mathrm{kg} / \mathrm{m}^{2}\right)$} & $26.29 \pm 5.19$ & $25.57 \pm 4.60$ & $26.85 \pm 5.60$ & 0.271 \\
\hline \multicolumn{2}{|c|}{ Systolic blood pressure $(\mathrm{mm} / \mathrm{Hg})$} & $132.51 \pm 25.19$ & $134.67 \pm 23.43$ & $130.83 \pm 26.61$ & 0.466 \\
\hline \multicolumn{2}{|c|}{ Diastolic blood pressure $(\mathrm{mm} / \mathrm{Hg})$} & $80.41 \pm 14.66$ & $79.41 \pm 13.89$ & $80.89 \pm 15.37$ & 0.110 \\
\hline \multicolumn{2}{|c|}{ Blood glucose (mg/dL) } & $108.26 \pm 23.93$ & $104.14 \pm 22.35$ & $111.48 \pm 24.86$ & 0.170 \\
\hline \multirow{2}{*}{ Nutritional status n (\%) } & Normal weight & $38(46.3)$ & $19(50)$ & $19(50)$ & \multirow{2}{*}{0.301} \\
\hline & Overweight & $44(53.7)$ & $17(38.6)$ & $27(61.4)$ & \\
\hline \multirow{3}{*}{$\begin{array}{l}\text { Antipsychotic } \\
\text { Administered n (\%) }\end{array}$} & Typical & $54(65.1)$ & $22(40.7)$ & $32(59.3)$ & \multirow{3}{*}{0.423} \\
\hline & Atypical & $28(33.7)$ & $14(50)$ & $14(50)$ & \\
\hline & Dementia & $6(7.3)$ & $1(16.7)$ & $5(83.3)$ & \\
\hline \multirow{4}{*}{$\begin{array}{l}\text { Neuroleptic } \\
\text { Diseases } \\
\mathrm{n}(\%)\end{array}$} & Bipolar disorder & $8(9.8)$ & $5(62.5)$ & $3(37.5)$ & \multirow{4}{*}{0.231} \\
\hline & Depression & $19(23.2)$ & $10(52.6)$ & $9(47.4)$ & \\
\hline & Schizophrenia & $23(28.0)$ & $7(30.4)$ & $16(69.6)$ & \\
\hline & Other psychotic disorders & $26(31.7)$ & $13(50)$ & $13(50)$ & \\
\hline
\end{tabular}

Table 3. Effect of type of antipsychotic medication on blood glucose levels by the duration of treatment.

\begin{tabular}{|c|c|c|c|c|c|c|}
\hline \multirow{2}{*}{ Fasting blood sugar } & \multirow{2}{*}{ Antipsychotics } & \multirow{2}{*}{$\begin{array}{l}\text { General } \\
\text { population }\end{array}$} & \multirow{2}{*}{ P-value } & \multicolumn{2}{|c|}{ Duration of treatment } & \multirow{2}{*}{ P-value } \\
\hline & & & & $\leq 6$ months & $>6$ months & \\
\hline Hyperglycemia & Typical & $115.74 \pm 18.63$ & \multirow{2}{*}{0.120} & $114.31 \pm 17.87$ & $116.48 \pm 19.33$ & 0.738 \\
\hline Blood glucose $\geq 100 \mathrm{mg} / \mathrm{dL}$ & Atypical & $124.74 \pm 23.31$ & & $121.38 \pm 24.75$ & $127.18 \pm 23.10$ & 0.606 \\
\hline Pre-diabetes & Typical & $118.07 \pm 4.84$ & \multirow{2}{*}{0.989} & $117.20 \pm 3.89$ & $118.50 \pm 5.40$ & 0.642 \\
\hline Blood glucose (110-125mg/dL) & Atypical & $118.09 \pm 3.41$ & & $117.20 \pm 1.42$ & $118.83 \pm 3.41$ & 0.459 \\
\hline
\end{tabular}

Table 4. Prevalence of hyperglycemia by risk factors and duration of treatment.

\begin{tabular}{|c|c|c|c|c|c|c|}
\hline \multirow[b]{2}{*}{ Variable } & & \multirow{2}{*}{$\begin{array}{l}\text { General } \\
\text { population }\end{array}$} & \multirow[b]{2}{*}{ P-value } & \multicolumn{2}{|c|}{ Duration of treatment } & \multirow[b]{2}{*}{ P-value } \\
\hline & & & & $\begin{array}{l}\leq 6 \text { months } \\
\text { n }(\%)\end{array}$ & $\begin{array}{l}>6 \text { months } \\
\text { n }(\%)\end{array}$ & \\
\hline \multirow{2}{*}{ Sex } & Woman & $27(47.4)$ & \multirow{2}{*}{0.472} & $9(33.3)$ & $18(66.7)$ & \multirow{2}{*}{0.602} \\
\hline & Man & $30(52.6)$ & & $12(40)$ & $18(60)$ & \\
\hline \multirow{2}{*}{ Age } & $<35$ years & $40(70.2)$ & \multirow{2}{*}{0.213} & $15(37.5)$ & $25(62.5)$ & \multirow{2}{*}{0.874} \\
\hline & $\geq 35$ years & $17(29.8)$ & & $6(35.3)$ & $11(64.7)$ & \\
\hline \multirow{2}{*}{ Education level } & At most primary & $4(7)$ & \multirow{2}{*}{0.207} & $1(25)$ & $3(75)$ & \multirow{2}{*}{0.611} \\
\hline & $\geq$ Secondary & $53(93)$ & & $20(37.7)$ & $33(62.3)$ & \\
\hline \multirow{2}{*}{ Marital status } & Single & $36(63.2)$ & \multirow{2}{*}{0.106} & $15(41.7)$ & $21(58.3)$ & \multirow{2}{*}{0.323} \\
\hline & Married & $21(36.8)$ & & $6(28.6)$ & $15(71.4)$ & \\
\hline \multirow{2}{*}{ Nutritional status } & Normal & $30(52.6)$ & \multirow{2}{*}{0.085} & $13(43.3)$ & $17(56.7)$ & \multirow{2}{*}{0.284} \\
\hline & Overweight & $27(47.4)$ & & $8(29.6)$ & $19(70.4)$ & \\
\hline \multirow{2}{*}{ Antipsychotics types } & Typical & $38(66.7)$ & \multirow{2}{*}{0.815} & $13(34.2)$ & $25(65.8)$ & \multirow{2}{*}{0.560} \\
\hline & Atypical & $19(33.3)$ & & $8(42.1)$ & $11(57.9)$ & \\
\hline \multirow{5}{*}{ Neuroleptics diseases } & Dementia & $4(7)$ & \multirow{5}{*}{0.451} & $0(0)$ & $4(100)$ & \multirow{5}{*}{0.031} \\
\hline & Bipolar disorder & $6(10.5)$ & & $5(83.3)$ & $1(16.7)$ & \\
\hline & Depression & $10(17.6)$ & & $3(30)$ & $7(70)$ & \\
\hline & Schizophrenia & $18(31.6)$ & & $4(22.2)$ & $14(77.8)$ & \\
\hline & Other psychotic disorders & $19(33.3)$ & & $9(47.4)$ & $10(52.6)$ & \\
\hline
\end{tabular}


Table 5. Independent predictors of hyperglycemia in patients with psychosis in the general population.

\begin{tabular}{llll}
\hline Predictors of Hyperglycemia & & OR (95\% CI) & P-value \\
\hline \multirow{2}{*}{ Sex } & Woman & 1 & 0.473 \\
Age & Man & $1.41(0.54-3.64)$ & 0.216 \\
Education level & $<35$ years old & $1.84(0.69-4.88)$ & 0.219 \\
& $\geq 35$ years old & 1 & \\
Marital status & At most primary & 1 & 0.110 \\
& $\geq$ Secondary & $2.52(0.57-11.03)$ & 0.088 \\
Nutritional status & Single & $2.18(0.83-5.67)$ & \\
& Married & 1 & 0.815 \\
Antipsychotics types & Normal & 1 & 0.733 \\
& Overweight & $0.42(0.15-1.13)$ & 0.549 \\
Neuroleptics diseases & Typical & $1.12(0.42-3.01)$ & 0.558 \\
& Atypical & 1 & 0.753 \\
\hline
\end{tabular}

Table 6. Correlation between some risk factors for diabetes.

\begin{tabular}{|c|c|c|c|c|c|c|c|}
\hline & Age & Sex & BMI & Hyperglycemia & $\begin{array}{l}\text { Duration of } \\
\text { treatment }\end{array}$ & $\begin{array}{l}\text { Type of } \\
\text { antipsychotic }\end{array}$ & $\begin{array}{l}\text { Neuroleptic } \\
\text { disease }\end{array}$ \\
\hline Age & 1 & $\begin{array}{l}r=-0,154 \\
p=0,166\end{array}$ & $\begin{array}{l}r=0,050 \\
p=0,653\end{array}$ & $\begin{array}{l}r=-0,138 \\
p=0,218\end{array}$ & $\begin{array}{l}\mathrm{r}=-0,037 \\
\mathrm{p}=0,744\end{array}$ & $\begin{array}{l}\mathrm{r}=0,078 \\
\mathrm{p}=0,486\end{array}$ & $\begin{array}{l}\mathrm{r}=-0,224^{*} \\
\mathrm{p}=0,043\end{array}$ \\
\hline Sex & $\begin{array}{l}r=-0,154 \\
p=0,166\end{array}$ & 1 & $\begin{array}{l}r=-0,489^{* *} \\
\mathrm{p}=0,0001\end{array}$ & $\begin{array}{l}r=0,079 \\
p=0,478\end{array}$ & $\begin{array}{l}r=0,0001 \\
p=1,000\end{array}$ & $\begin{array}{l}r=-0,154 \\
p=0,166\end{array}$ & $\begin{array}{l}r=0,305^{* *} \\
p=0,005\end{array}$ \\
\hline BMI & $\begin{array}{l}r=0,050 \\
p=0,653\end{array}$ & $\begin{array}{l}r=-0,489^{* *} \\
\mathrm{p}=0,0001\end{array}$ & 1 & $\begin{array}{l}r=-0,190 \\
p=0,087\end{array}$ & $\begin{array}{l}r=0,114 \\
p=0,307\end{array}$ & $\begin{array}{l}r=0,308^{* *} \\
\mathrm{p}=0,005\end{array}$ & $\begin{array}{l}r=-0,227^{*} \\
p=0,040\end{array}$ \\
\hline Hyperglycemia & $\begin{array}{l}r=-0,138 \\
\mathrm{p}=0,218\end{array}$ & $\begin{array}{l}r=0,079 \\
p=0,478\end{array}$ & $\begin{array}{l}r=-0,190 \\
p=0,087\end{array}$ & 1 & $\begin{array}{l}\mathrm{r}=0,215 \\
\mathrm{p}=0,053\end{array}$ & $\begin{array}{l}r=-0,026 \\
p=0,817\end{array}$ & $\begin{array}{l}r=0,095 \\
p=0,396\end{array}$ \\
\hline Duration of treatment & $\begin{array}{l}r=-0,037 \\
p=0,744\end{array}$ & $\begin{array}{l}r=0,0001 \\
p=1,000\end{array}$ & $\begin{array}{l}r=0,114 \\
p=0,307\end{array}$ & $\begin{array}{l}\mathrm{r}=0,215 \\
\mathrm{p}=0,053\end{array}$ & 1 & $\begin{array}{l}r=0,088 \\
p=0,429\end{array}$ & $\begin{array}{l}r=-0,022 \\
p=0,844\end{array}$ \\
\hline Type of antipsychotic & $\begin{array}{l}r=0,078 \\
p=0,86\end{array}$ & $\begin{array}{l}r=-0,154 \\
p=0,166\end{array}$ & $\begin{array}{l}r=0,308^{* *} \\
\mathrm{p}=0,005\end{array}$ & $\begin{array}{l}r=0,026 \\
p=0,817\end{array}$ & $\begin{array}{l}r=-0,088 \\
p=0,429\end{array}$ & 1 & $\begin{array}{l}r=-0,042 \\
p=0,710\end{array}$ \\
\hline Neuroleptic disease & $\begin{array}{l}r=-0,224^{*} \\
\mathrm{p}=0,043\end{array}$ & $\begin{array}{l}r=0,305^{* *} \\
\mathrm{p}=0,005\end{array}$ & $\begin{array}{l}r=-0,227^{*} \\
p=0,040\end{array}$ & $\begin{array}{l}\mathrm{r}=0,095 \\
\mathrm{p}=0,396\end{array}$ & $\begin{array}{l}r=-0,022 \\
p=0,844\end{array}$ & $\begin{array}{l}r=-0,042 \\
p=0,710\end{array}$ & 1 \\
\hline
\end{tabular}

* Correlation significant at $\mathrm{p}<0.05 * *$ Correlation significant at $\mathrm{p}<0.01$.

\section{Discussion}

Chronic hyperglycemia in diabetes is associated with longterm damage, dysfunction, and failure of various organs, particularly the eyes, kidneys, nerves, heart, and blood vessels. Hence, good blood glucose management remains one of the key issues in the prevention and treatment of diabetes, which is a cause of death worldwide.

The results of this study show that hyperglycemia is observed in both typical and atypical patients undergoing antipsychotic treatment (Table 3). This observation is consistent with the study of Kessing et al. [9] which found that in clinical practice, treatment with first and secondgeneration antipsychotics was associated with an increased risk of diabetes. However, blood glucose levels were higher in patients treated with atypical antipsychotic drugs compared to patients treated with typical antipsychotic drugs (Table 3). This could be partly explained by the fact that atypical antipsychotic drugs block both dopamine and serotonin receptors, leading more often to altered carbohydrate metabolism via the development of insulin resistance, than some typical antipsychotic drugs, which block dopamine receptors more [15]. This corroborates the study by Wani et al. [16] who found that some atypical antipsychotic drugs such as Olanzapine, increase fasting blood sugar levels more than typical antipsychotic drugs such as Haloperidol. However, our study showed that treatment with the different classes of antipsychotics was associated with high plasma glucose levels $\geq 100 \mathrm{mg} / \mathrm{dL}$, which increased over time in patients on treatment for more than six months $(116.48 \pm 19.33 \mathrm{mg} / \mathrm{dL}$ for typical antipsychotics and $127.18 \pm 23.10 \mathrm{mg} / \mathrm{dL}$ for atypical antipsychotics) compared with those of up to 6 months $(114.31 \pm 17.87 \mathrm{mg} / \mathrm{dL}$ for typical antipsychotics and $121.38 \pm 24.75 \mathrm{mg} / \mathrm{dL}$ for atypical antipsychotics) (Table 3). These results may be explained by the administration of long-term neuroleptic drugs. It is following a research by El sheikh et al. [17] who found an increase in fasting blood sugar levels in patients with schizophrenia after six months of treatment.

Knowledge of the factors associated with a high risk of hyperglycemia can help to identify among patients on 
antipsychotic therapy those who are needy of monitoring or intervention. This study found that for all risk factors studied, the prevalence of hyperglycemia was higher in patients on antipsychotic treatment for more than 6 months (Table 4); with a positive but non-significant correlation between hyperglycemia and duration of treatment $(\mathrm{r}=0.215$; $\mathrm{p}=0.053)$ (Table 6). This may be explained by the effect of antipsychotics on 5HT2C receptors. These results are consistent with the study of Howes et al. [18] which showed that $55 \%$ of patients developed blood glucose abnormalities within 4 months after initiation of clozapine therapy, regardless of changes in insulin resistance or body mass index. However, men were more affected by hyperglycemia $(52.6 \%)$ and were 1.41 times more likely to develop hyperglycemia than women. This could be explained by the presence of female sex hormones such as progesterone and estrogen, which have a protective effect on the alteration of blood sugar levels in women [19]. This is consistent with the results of Cohen et al. [20] who showed an alteration in fasting blood glucose levels in men with schizophrenia compared to women. This study also found that patients with an age $<35$ years were more affected by hyperglycemia $(70.2 \%)$ and were 1.84 times more likely to develop hyperglycemia than patients with an age $\geq 35$ years (Table 4 ). These results could be explained by the fact that patients in the $<35$ age group included in our study would likely have a genetic predisposition to carbohydrate abnormalities and therefore taking antipsychotics would precipitate the onset of these glucose regulation abnormalities. This is consistent with Hammerman et al. [21] who showed that the association between diabetes and antipsychotic drug use was stronger in younger age groups compared to older patients. Hyperglycemia was more prevalent in single patients $63.2 \%$ versus $36.8 \%$ in married patients; with a risk of hyperglycemia of 2.18 in single patients. This could be explained by the fact that unmarried patients would have less attention, care, and monitoring from their relatives than married patients. These results are consistent with those of Zafar et al. [22] who showed that hyperglycemia was more prevalent in single patients with chronic schizophrenia compared to married. Patients on typical antipsychotic treatment were more affected by hyperglycemia $66.7 \%$ versus $33.3 \%$ in patients on atypical antipsychotic treatment; with 1.12 times the risk of developing hyperglycaemia (Table 5). This observation is consistent with the study by Lipscombe et al. [23] which showed that the risk of hyperglycaemia was high for atypical $(\mathrm{OR}=1.44)$ and typical $(\mathrm{OR}=2.86)$ antipsychotic drugs. A positive correlation between BMI and duration of treatment $(r=0.114 ; p=0.307)$ was observed (Table 6). This is in line with the results in Table 4, which showed a prevalence of $61.4 \%$ in patients under antipsychotic treatment for more than 6 months. Similarly, a positive and significant correlation was obtained between BMI and type of antipsychotic drug ( $\mathrm{r}=0.308$; $\mathrm{p}=0.005$ ) (Table 6). This could be explained by lifestyle factors and side effects of antipsychotic medications or perhaps a complex interaction of these factors [24]. Indeed, numerous studies suggest that leptin and ghrelin, a multitude of peptides, hormones, and receptors associated with dietary intake and energy homeostasis are potentially involved in antipsychotic-induced weight gain [25]. This is consistent with the review study by Dayabandara et al. [26] which revealed the ability of antipsychotic drugs to induce weight gain. Our study also revealed that patients with schizophrenia and those with bipolar disorder were at increased risk of developing hyperglycemia 1.80 and 1.50 respectively. These results could be explained by the fact that biochemical changes due to mental illness would likely influence the frequency of hyperglycemia, following the use of antipsychotics and long term exposure to unhealthy lifestyle behaviors. This supports the study of Vancampfort et al. [27] which showed that patients with schizophrenia and those with bipolar disorder were at increased risk of developing type 2 diabetes compared to a group of healthy controls.

\section{Conclusion}

Our study shows that antipsychotic drug use and the type of neurological disease in patients with psychosis may be predictors of abnormalities in carbohydrate metabolism contributing to the development of overt diabetes. The risk of developing diabetes increases with the duration of treatment and with the type of antipsychotic (typical or atypical). Therefore, people with psychosis should be given special attention to the management of non-communicable diseases to reduce the burden of morbidity and mortality in this vulnerable population. Nevertheless, other factors could contribute to the development of this overt diabetes, such as lifestyle. This requires further study to determine their contribution to the development of diabetes in patients suffering from psychosis.

\section{Authors' Contributions}

OYMB, HRH designed the study plan and drafted the questionnaire; GMN, THD planned the work; HRH collected the data; MNW and BRTT analyzed the data; MNW, REKD, CSMB, HRH, and BRTT wrote the manuscript; GMN, THD, OYMB read and approved the final manuscript.

\section{Funding}

This work has not been supported by a grant or funding.

\section{Conflict of Interest}

The authors declare that the content of this article does not present any conflict of interest.

\section{Acknowledgements}

The authors express their thanks to the Jamot Hospital in Yaoundé and all the participants in the survey. 


\section{References}

[1] Maulik N, Reenu S, Rita M. (2016). Assessment of Oxidative Stress and Lipid Status in Patients of Type 2 Diabetes Mellitus with and without Complications. Int J Biochem Res Rev. 13 (1): $1-10$.

[2] Takuisssu NGR, Ngondi JL, Oben JE. (2020). Antioxidant and Glucose Lowering Effects of Hydroethanolic Extract of Baillonella toxisperma Pulp. J Food Res. 9 (2): 20-29.

[3] International Diabetes Federation. (2019). Diabetes Atlas, 9éme edition.

[4] Saeedi P, Petersohn I, Salpea P, et al. (2019). Global and regional diabetes prevalence estimates for 2019 and projections for 2030 and 2045: Results from the International Diabetes Federation Diabetes Atlas, 9th edition. Diabetes Res Clin Pract. 157: 1-10.

[5] Domino EM, Swartz SM. (2008). Who Are the New Users of Antipsychotic Medications? Psychiatr Serv. 59 (5): 507-514.

[6] Moreno-Kustner B, Martın C, Pastor L. (2018). Prevalence of psychotic disorders and its association with methodological issues. A systematic review and meta-analyses. PLoS ONE. 13 (4): e0195687.

[7] Jongsma HE, Turner C, Kirkbride JB, Jones PB. (2019). International incidence of psychotic disorders, 2002-17: a systematic review and meta-analysis. The Lancet Public Health. 4 (5): e229-e244.

[8] Holt RIG. (2019). Association between Antipsychotic Medication Use and Diabetes. Curr Diab Rep. 19: 96.

[9] Kessing LV, Thomsen AF, Mogensen UB, Andersen PK. (2010). Treatment with antipsychotics and the risk of diabetes in clinical practice. Br J Psychiatry. 197: 266-271.

[10] Robinson DJ, Coons M, Haensel H, Vallis M, Yale J-F. (2018). Diabetes and Mental Health. Can J Diabetes. 42: S130-S141.

[11] Saravane D. (2014). Metabolic complications of psychotropic drugs. PSN. 2 (12): 51-63.

[12] International Diabetes Federation. (2005). The IDF consensus worldwide definition of the metabolic syndrome. 1-7.

[13] Alberti KG, Zimmet PZ. (1998). Definition, diagnosis and classification of diabetes mellitus and its complications: Part 1: diagnosis and classification of diabetes mellitus provisional report of a WHO consultation. Diabet Med. 15 (7): 539-553.

[14] World Health Organization. (2003). Diet, nutrition and the prevention of chronic diseases. Technical Reports Series, No. 916. World Health Organization, Geneva.
[15] Liberty FI, Todder D, Umansky R, Harman-Boehm I. (2004). Atypical Antipsychotics and Diabetes Mellitus: An Association. IMAJ. 6: 276-279.

[16] Wani RA, Dar MA, Margoob MA, Rather YH, Haq I, Shah MS. (2015). Diabetes mellitus and impaired glucose tolerance in patients with schizophrenia, before and after antipsychotic treatment. J Neurosci Rural Pract. 6 (1): 17-22.

[17] El Sheikh MW, Rajab ZA, Shalaby SA, Shaheen GA. (2019). Comparison between typical and atypical antipsychotics according their effects on metabolism in schizophrenia patients. Menoufia Med J. 32: 80-87.

[18] Howes OD, Bhatnagar A, Gaughran FP, Amiel SA, Murray RM, Pilowsky LS. (2004). A Prospective Study of Impairment in Glucose Control Caused by Clozapine without Changes in Insulin Resistance. Am J Psychiatry. 161 (2): 361-363.

[19] Gupte AA, Pownall HJ, Hamilton DJ. (2015). Estrogen: An Emerging Regulator of Insulin Action and Mitochondrial Function. J Diabetes Res. 1-9.

[20] Cohen D, Stolk RP, Grobbee DE, Gispen-de Wied CC. (2006). Hyperglycemia and Diabetes in Patients with Schizophrenia or Schizoaffective Disorders. Diabetes Care. 29 (4): 786-791.

[21] Hammerman A, Dreiher J, Klang SH, Munitz H, Cohen AD, Goldfracht M. (2008). Antipsychotics and Diabetes: An AgeRelated Association. Ann Pharmacother. 42 (9): 1316-1322.

[22] Zafar H, Zohra KN, Jawed AD, Iqbal A. (2011). Hyperglycemia and treatment with antipsychotics a study from a tertiary care centre. JPPS. 8 (2): 69-73.

[23] Lipscombe LL, Lévesque LE, Gruneir A, et al. (2011). Antipsychotic Drugs and the Risk of Hyperglycemia in Older Adults without Diabetes: A Population-Based Observational Study. Am J Geriat Psychiat. 19 (12): 1026-1033.

[24] Holt RIG, Peveler RC. (2009). Obesity, serious mental illness and antipsychotic drugs. Diabetes Obes Metab. 11: 665-679.

[25] Correll CU, Lencz T, Malhotra AK. (2011). Antipsychotic drugs and obesity. Trends Mol Med. 17 (2): 97-107.

[26] Dayabandara M, Hanwella R, Ratnatunga S, Seneviratne S, Suraweera C, de Silva V. (2017). Antipsychotic-associated weight gain: management strategies and impact on treatment adherence. Neuropsych Dis Treat. 13: 2231-2241.

[27] Vancampfort D, Correll CU, Galling B, Probst M, De Hert M, Ward PB, Rosenbaum S, Gaughran F, Lally J, Stubbs B. (2016). Diabetes mellitus in people with schizophrenia, bipolar disorder and major depressive disorder: a systematic review and large scale meta-analysis. World Psychiatry. 15 (2) 166-174. 